\title{
ENTAMGEBA VARANI N. SP. AMIBE PARASITE DE REPTILE
}

\author{
Par G. LAVIER
}

Ayant eu l'occasion d'autopsier dix Varanus niloticus provenant des bords du lac Victoria à Entebbé, j'ai rencontré chez un unique individu une infection par une amibe intestinale.

A l'examen direct, ce parasite présente un endoplasme et un ectoplasme nettement délimités ; le noyau n'est pas visible ; l'émission de pseudopodes se fait avec une grande activité ; les inclusions alimentaires sont rares et la plupart des exemplaires que j'ai observés en étaient dépourvus; l'amibe qui fait l'objet de la

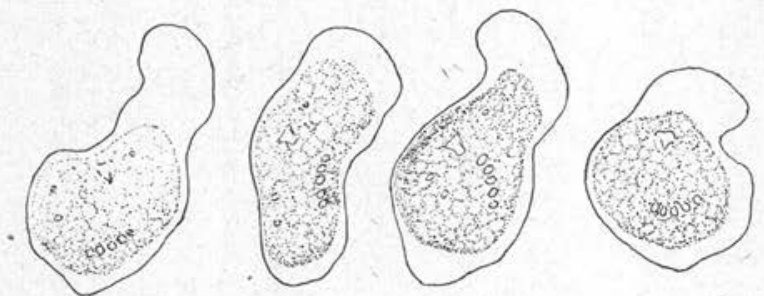

Fig. 1. - Entamœba varani; aspect à l'état frais, quatre croquis du même individu à 10 secondes d'intervalle.

figure 1 est donc à ce point de vue une exception ; elle avait phagocité une chaînette de Coccus qui peut servir de repère pour le mouvement.

Après fixation et coloration à l'hématoxyline ferrique, cette amibe se présente sous la forme d'individus arrondis mesurant de 12 à $25 \mu$ de diamètre (fig. 2). Le noyau mesure environ $5 \mu$ de diamètre ; il offre un aspect identique à celui de l'Entamœba dysenteriæ: membrane externe avec fines granulations chromatiques et caryosome central. La multiplication se fait par division binaire; je n'ai pu toutefois en observer les détails mais seulement la fin (fig. 2, 6).

La plupart des individus que j'ai rencontrés dans les frottis présentaient une vacuole glycogénique déjà bien développée et correspondaient done au stade prékystique (fig. 2, 2 et 3 ). Je n'ai $\mathrm{pu}$ toutefois rencontrer de kystes; mais le noyau d'un certain

Annales de Parasitologie, T. VI, $\mathrm{N}^{\circ} 2 .-1^{\text {er }}$ avril 1928 , p. 152-154. 
nombre d'individus présentait un début de mitose, semblant plutôt correspondre à une mitose d'enkystement qu'à une division végétative (fig. 2,5 ). On voit dans ce cas le caryosome s'allonger puis se

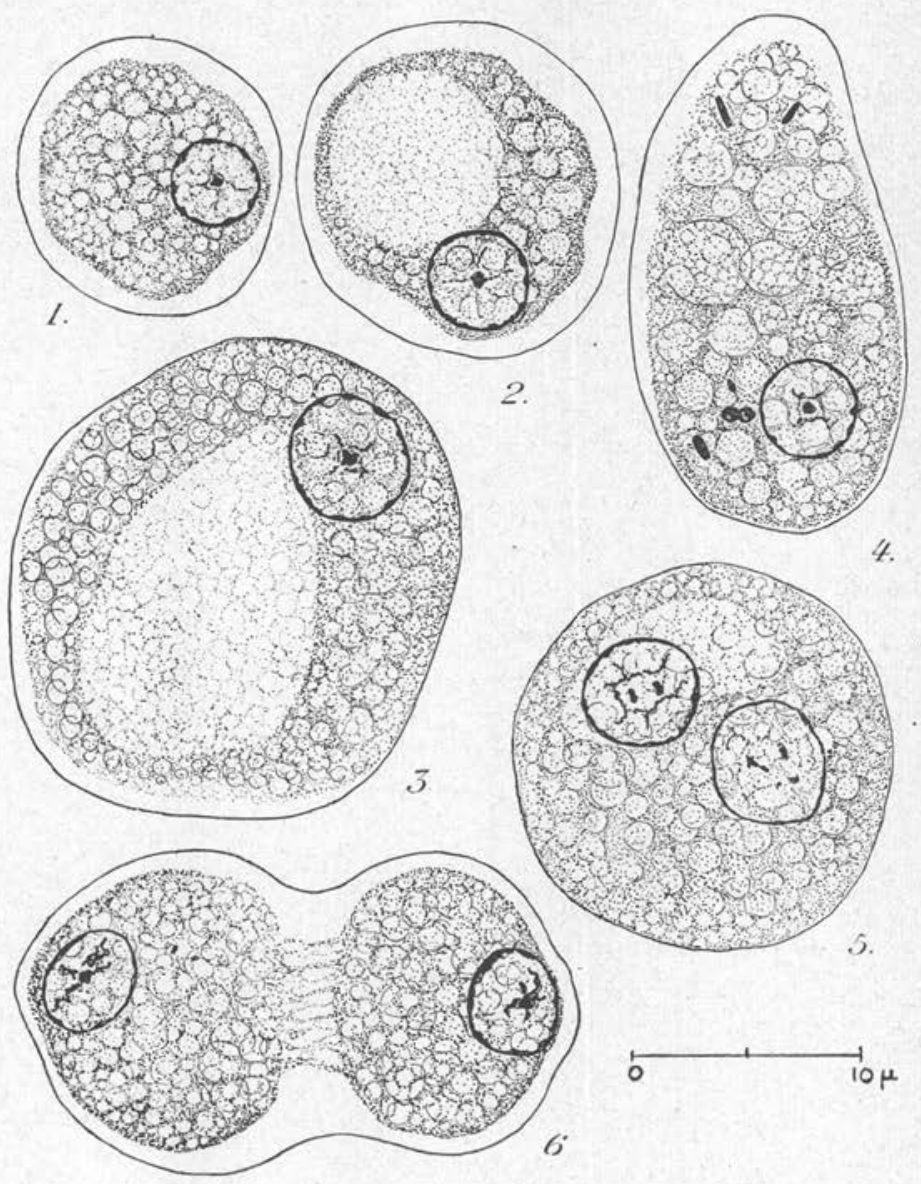

Fig. 2. - Entamæba varani, après fixation au liquide de Bouin et coloration à l'hématoxyline ferrique.

dédoubler ; la chromatine périphérique quitte la paroi et se rassemble en huit chromosomes (fig. 3 ) ; je n'ai pu observer le phénomène au delà de ce stade.

Cette amibe se rencontrait assez facilement dans les deux tiers postérieurs de l'intestin du varan parasité; l'aspect de la $\mathrm{mu}$ queuse ne permet pas de lui attribuer un rôle pathogène. 
Cette amibe est à ma connaissance la première signalée chez Varanus niloticus. Dobell (1914) a figuré une amibe du type Entamœeba coli qu'il avait rencontrée chez un lézard ; Lacerta muralis ; c'est sans doute la même espèce ou une espèce très voisine qu'ont signalé Wenyon (1921) chez Lacerta agilis et Agama stellio, et Franchini (1921) chez Lacerta ocellata. Les caractères nucléaires de l'amibe du varan ne permettent pas de la rattacher à cette oú
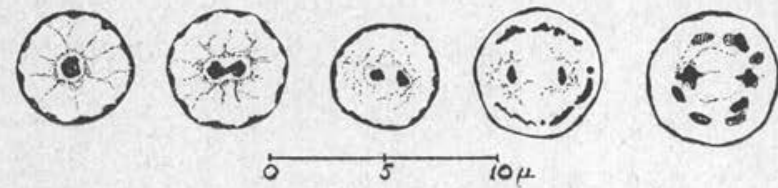

Fıg. 3. - Début de la mitose; de gauche à droite : le noyau à l'état de repos ; étirement du caryosome; dédoublement du caryosome; rassemblement de la chromatine périphérique; formation de huit chromosomes.

à ces espèces ; ils la situent au contraire très près de l'Entamœba dysenteriæ ou de l'Entamoba ranarum; il est même permis de se demander si l'on n'aurait pas affaire à cette dernière espèce, le varan ayant pu s'infecter en dévorant des têtards. Cependant cette dernière hypothèse est peu vraisemblable: étant donné l'étroite spécificité parasitaire des amibes intestinales, il y a peu de chance que cette amibe de batracien puisse s'implanter chez un hôte aussi éloigné zoologiquement; en outre le varan examiné avait subi, avant d'être sacrifié, trois semaines de captivité et de jeûne ; il s'agissait donc d'une infection déjà d'assez longue durée.

Je propose pour cette nouvelle espèce le nom d'Entamœba varani.

\section{BiBLIOGRAPHIE}

Doberl (C.). - Cytological Studies on three species of Amœba: A. lacerta Hartmann; A. gleba n. sp.; A. fluvialis n. sp. Arch. f. Protistenk., XXXIV, 1914, p. 139.

Franchini. - Sur les flagellés intestinaux du type Herpetomonas du Chameleon vulgaris et leur culture, et sur les flagellés du type Herpetomonas de Chalcides (Gongylus) ocellatus et Tarentola mauritanica. Bull. Soc. path. exot., XIV, 1921, p. 641.

Wenyon. - Observations on the Intestinal Protozoa of three Egyptian Lizards, with a Note on a Cell-invading Fungus. Parasitology, XII, 1921, p. 350. 